\title{
O império dos hormônios e a construção da diferença entre os sexos
}

\section{The reign of hormones and the construction of gender differences}

\section{Fabíola Rohden}

Pesquisadora do Centro Latino-americano em Sexualidade e Direitos Humanos Instituto de Medicina Social / Universidade do Estado do Rio de Janeiro Rua Felício dos Santos, 66, apto. sub-202 20240-240 Rio de Janeiro - RJ - Brasil

fabiola@ims.uerj.br

Recebido para publicação em abril de 2007. Aprovado para publicação em novembro de 2008.
ROHDEN, Fabíola. O império dos hormônios e a construção da diferença entre os sexos. História, Ciências, Saúde Manguinhos, Rio de Janeiro, v.15, supl., p.133-152, jun. 2008.

A partir do debate teórico sobre gênero e ciência, discute os processos de redefinição das diferenças de gênero e sexo por meio de marcadores tidos como biológicos ou naturais. Identifica um percurso de naturalização das diferenças através de uma lógica de

'substancialização' ou 'materialização', a exemplo da percepção da medicina sobre a mulher, que promove modelos explicativos da economia corporal feminina centrados ora em órgãos como útero e ovários, ora na mecânica dos hormônios e, mais recentemente, também nas distinções genéticas e neurológicas. Aborda a trajetória da descoberta dos chamados hormônios sexuais e sua relação com a perspectiva dualista, no que se refere ao gênero. Demonstra como esses poderosos mensageiros químicos ajudaram a configurar a passagem entre uma lógica do excesso que envolvia o sexo até o final do século XIX, para o imperativo da falta, predominante desde meados do século XX.

Palavras-chave: gênero, sexualidade, hormônios, história da ciência, história da medicina.

ROHDEN, Fabíola. The reign of hormones and the construction of gender differences. História, Ciências, Saúde - Manguinhos, Rio de Janeiro, v.15, Suppl., p.133-152, June 2008.

Within the context of the theoretical debate on gender and science, the article discusses the process of redefining gender and sex differences using so-called biological or natural markers. It identifies how gender differences undergo naturalization using a logic of 'substantialization or 'materialization'. This process is exemplified in how medicine views women, promoting explanatory models of economics of the female body that are at times centered around organs like the uterus and ovaries, at other times centered on the mechanics of hormones, and, most recently, focused on genetic and neurological differences. More specifically, it follows the discovery of socalled sex hormones and its relation to a dualist perspective of gender. These powerful chemical messengers helped shaped the passage from the logic of excess surrounding sex through the late nineteenth century, to the imperative of insufficiency, prevalent since the mid-twentieth century.

Keywords: gender; sexuality; hormones; history of science; history of medicine. 
$\mathrm{N}$ os primeiros meses de 2007 assistimos ao lançamento, pela indústria farmacêutica, de duas grandes campanhas publicitárias. A primeira referia-se ao Distúrbio Androgênico do Envelhecimento (Daem) e foi divulgada pelo laboratório Schering. O anúncio tratava da 'andropausa', fenômeno "diretamente relacionado ao decréscimo da produção de testosterona após os 40 anos de idade", cujos principais sintomas incluem perda da libido (desejo sexual), diminuição da massa muscular, perda de energia, depressão e disfunção erétil, além do risco de doenças cardiovasculares (Época, 26 mar. 2007, p.11). A segunda campanha publicitária dizia respeito à promoção, no mercado europeu e sem previsão para lançamento no Brasil, do Intrinsa, medicamento da Procter \& Gamble, anunciado como o "viagra feminino". Trata-se de um adesivo que promete recuperar a libido de mulheres que entraram na menopausa precocemente, após passar por cirurgias de remoção de ovários e útero. Mais uma vez a substância em questão era a testosterona, "hormônio ligado ao desejo sexual", que seria reposto na corrente sanguínea (Época, 2 abr. 2007, p.28).

É cada vez mais comum depararmos com artigos em revistas e livros de divulgação científica, ou mesmo em jornais de grande circulação, e com programas de televisão dedicados a tratar da importância dos hormônios no bem-estar e na saúde dos indivíduos e na determinação de certos comportamentos. Quanto mais atual for a matéria, maior será a probabilidade de que trate também da conexão entre cérebro e hormônios e que apresente as diferenças inatas e intransponíveis entre os sexos. A idéia de que os hormônios determinam tudo, até mesmo nossa inteligência e nosso comportamento frente ao sexo oposto, parece ganhar cada vez mais adeptos. Fala-se também em inteligência hormonal. Assistimos ao império de um 'corpo hormonal' que parece sobrepor-se a qualquer outra concepção biomédica corrente, pelo menos se considerarmos o sucesso de sua aceitação entre um público cada vez mais amplo.

Observa-se que as mulheres têm sido o foco mais freqüente nos discursos sobre esse corpo hormonal, tanto no âmbito científico quanto na divulgação para leigos. Isso ocorre, por exemplo, quando se fala da fisiologia feminina e de como a vida das mulheres é 'indiscutivelmente' governada pelas transformações hormonais inerentes aos seus estados cíclicos e instáveis. Fenômenos como a tensão pré-menstrual (TPM) ou as transformações percebidas com a menopausa têm sido usados como chaves explicativas para as mais variadas formas de comportamento e têm alimentado uma grande indústria de tratamento dos 'problemas femininos'. Além disso, os hormônios estariam na base das diferenças intelectuais entre homens e mulheres, 'fato' contra o qual pouco se poderia fazer. A recomendação freqüente é para que se compreendam e admitam essas distinções essenciais.

O objetivo deste artigo é entender algumas facetas da gênese dessas idéias e o porquê de seu grande apelo. A proposta é contextualizar a produção científica considerando a interação entre o meio social, a atuação dos cientistas e os produtos desenvolvidos. Nesse caso especificamente, a análise das relações de gênero é imprescindível, já que sugiro que certas tomadas de posição decorrem exatamente das tensões relativas ao gênero. Trata-se de processos com múltiplas origens e resultados até mesmo inesperados, quando analisamos a intenção dos cientistas, o peso das universidades ou institutos de pesquisa, a força dos laboratórios, o cenário dos movimentos sociais envolvidos e mesmo o jogo político mais amplo. Mas é possível, sem dúvida, reconhecer certos vetores que nos levam a pensar sobre 
dilemas mais profundos de nossa sociedade. A história dos hormônios é um desses casos capazes de revelar algo dessa natureza, e a dimensão do gênero tem aí um grande papel.

Uma forma bastante eficaz de demonstrar essa preeminência de um modelo de corpo hormonal é a descrição do que ocorreu nas concepções médicas por volta de 1900. Em curto período, verifica-se uma mudança extremamente significativa no que se refere ao entendimento do corpo e do comportamento femininos. Para demonstrar tal movimento, recorro aos argumentos contidos em trabalhos científicos, como teses apresentadas à Faculdade de Medicina do Rio de Janeiro, artigos e anúncios em periódicos e debates em instituições médicas. Esse material certamente ganha nova luz quando cotejado com o panorama do desenvolvimento da pesquisa internacional sobre hormônios.

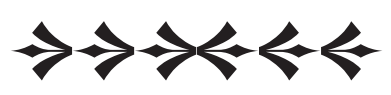

A grande transformação ocorrida no período refere-se à passagem de um momento em que os órgãos reprodutivos femininos, especialmente os ovários, são percebidos como os grandes responsáveis pelas perturbações de ordem física e mental das mulheres, pregandose sua extração cirúrgica, para outro momento em que são apresentados os malefícios originados pela 'insuficiência ovariana', prescrevendo-se alguma forma de reposição das secreções produzidas pelos ovários. Essas secreções passam, então, a ser vistas como fundamentais para o bom funcionamento do organismo feminino e para o equilíbrio mental da mulher. Antes de apresentar os relatos referentes a essa trajetória, cabe enfatizar que havia uma perspectiva dominante na cena médica brasileira, mas não só nela, que identificava nos órgãos sexuais/reprodutivos o centro da economia corporal feminina. A mulher seria governada pelos ciclos relacionados à reprodução, desde a puberdade, gravidez e amamentação até a menopausa. Praticamente todo o comportamento feminino poderia ser explicado em função disso, inclusive o que era percebido como desordem. ${ }^{1}$

A partir da segunda metade do século XIX, a relação entre órgãos genitais, sexualidade feminina e doenças de caráter amplo e instável constituiu um dos principais focos da atenção dos médicos. Para cuidar das doenças, eles se dedicaram ao desenvolvimento de um leque significativo de meios de tratamento, que incluíam cirurgias e reclusão. ${ }^{2}$ Além disso, em alguns casos, como o da loucura puerperal, as perturbações femininas poderiam ter conseqüências que extrapolavam o domínio individual, chegando, na visão dos médicos, a atingir a sociedade como um todo, uma vez que eram percebidas como determinantes na execução de atos considerados nocivos ao bem público, como no crime de infanticídio. $\mathrm{Na}$ realidade, tratava-se de um terreno de desordens que passava pelo corpo, mente e moralidade femininas e chegava até a sociedade. E é sobre esse vasto e indefinido terreno que os médicos, em especial, os ginecologistas e obstetras, atuaram (ver Rohden, 2003).

Na produção médica editada no Brasil, a associação entre órgãos genitais femininos e suas funções e perturbações mentais aparece sob diversas formas, desde a histeria até a loucura puerperal. No que se refere à menstruação, por exemplo, a partir da década de 1890 assiste-se a um redescobrimento desse tema, marcado pela interpretação da desordem. ${ }^{3} \mathrm{~A}$ menstruação expressa de uma maneira única o caráter instável e suscetível da constituição física e mental da mulher. Nas fases críticas de seu aparecimento, na puberdade, e de seu 
fim, na menopausa, e também durante todo o período de sua recorrência, a mulher estaria sujeita a intensas perturbações. É quase como se a mulher, por sua própria natureza, beirasse a patologia. As manifestações dessa condição, diagnosticadas pelos médicos, embora pudessem assumir caracteres físicos eram principalmente de ordem mental. Na realidade, a relação entre esses dois domínios é de tal forma intrincada que, às vezes, determinar qual se sobrepõe ao outro torna-se mesmo impossível. Os genitais pareciam ter uma capacidade singular de interferência na estrutura da mente feminina.

É a partir desse contexto que podemos entender a forte referência a intervenções cirúrgicas para tratamento de variados males que acometiam as mulheres, particularmente a prática da castração ovariana ou ovariotomia, bastante citada. ${ }^{4}$ Essa cirurgia seria, a princípio, empregada para extirpar ovários doentes, tomados por quistos. Sua aplicação, entretanto, se tornou cada vez mais abrangente, e passou a ser comum a menção a esse tipo de cirurgia como recurso para curar definitivamente as perturbações mentais ligadas aos órgãos genitais. $^{5}$

A ovariotomia começa a aparecer nas teses da Faculdade de Medicina do Rio de Janeiro a partir de 1866. Nas décadas de 1870 e 1880 capta o maior número de interessados. Posteriormente, só há uma referência no ano de 1895 (Maia, 1866; Rego, 1871; Vasconcellos, 1872; Silva, 1873; Carvalho, 1873; Santos Filho, 1873; Silva, 1878; Fontes, 1880; Assis, 1881; Silva, 1881; Falcão, 1881; Araujo, 1881; Gomes, 1883; Nunes, 1883; Silva, 1883; Vasconcellos, 1895). Nesse conjunto de teses não encontramos casos em que a ovariotomia fosse direta ou exclusivamente recomendada para pôr fim às desordens mentais. As teses sempre focalizam em primeiro plano a cura dos quistos ovarianos. Mas em todas elas há sempre uma referência, mesmo que indireta, à relação com os problemas mentais. Refletia-se no Brasil o imenso debate que ocorria na Europa e nos Estados Unidos a respeito dessa questão.

O trabalho de José Rodrigues dos Santos Filho (1873) ressalta, exatamente, que a ovariotomia tinha sido alvo de uma grande polêmica, tendo finalmente ocupado o seu legítimo posto a serviço da humanidade. Segundo ele, era uma das técnicas mais importantes do arsenal cirúrgico da época. Praticada desde o início do século, tinha proporcionado na Inglaterra a glória de muitos médicos a partir da década de 1840, entre eles os famosos Spencer Wells e I. Backer-Brown. A França tinha historicamente se mostrado mais resistente. No Brasil a ovariotomia foi tentada pela primeira vez em 1839 e depois em 1865 pelo doutor Saboia, já com sucesso. Em 1870 Feijó Filho também praticou a operação de extirpação dos ovários. Apesar de não fazer referências diretas à relação com as perturbações mentais, Santos Filho menciona que a ovariotomia se originou na tentativa, por parte de um pai, de coibir os desejos sexuais da filha por meio da castração. Um dos ingleses citados por ele, I. Backer-Brown, esteve envolvido em extensa polêmica que teve origem em abusos cometidos com castração e cliteridectomia visando eliminar excessos sexuais femininos (Rohden, 2001, p.75-76; Kent, 1990; Scull, Favreau, 1986).

A tese de Miguel Archanjo da Silva (1873) é mais explícita ao dizer que se empregava a ovariotomia para "coibir a sensualidade de certas mulheres debochadas" (p.8). Afirma que essa cirurgia tinha levantado injustamente suspeitas entre médicos e naquele momento recobrava o seu devido valor. Um dos problemas evocados era o alto índice de mortalidade 
que provocava e que, na ocasião, teria diminuído bastante. Cita as estatísticas de Spencer Wells para provar esses resultados. Nas quinhentas ovariotomias praticadas pelo ginecologista inglês, a mortalidade tinha sido de 'apenas' $25,4 \%$, número que Silva considerava bastante satisfatório.

Ao longo do tempo, a idéia da cura de perturbações mentais pela cirurgia vai ganhando respaldo, e as teses começam a tratar da questão de forma mais aprofundada. Já na passagem do século, o tema, que estava na ordem do dia, torna-se objeto de avaliações bem discordantes. A tese de Urbano Garcia, Da intervenção cirúrgico-ginecológica em alienação mental, defendida em 1901, representa bem o lado dos defensores da cirurgia. Garcia relata que esse era um dos assuntos mais palpitantes entre os médicos da época e, baseado em casos assistidos em vários hospitais, afirma que a intervenção cirúrgica seria também o futuro da psiquiatria. Segundo ele, os dados do diretor do asilo de Londres, Hobbs, apresentados no congresso anual da Associação Médica Britânica, comprovariam os resultados positivos das intervenções. De oitenta casos, entre $30 \%$ e $37,5 \%$ das pacientes se restabeleceram; entre $18 \%$ e $22,5 \%$, melhoraram consideravelmente; entre $28 \%$ e $35 \%$ não sofreram nenhuma alteração; e em apenas $4 \%$ ou $5 \%$ dos casos houve morte (Garcia, 1901, p.9).

Para o autor, as operações davam bons resultados porque os órgãos reprodutivos atuariam sobre a atividade do cérebro. Nesse sentido, faz o seguinte comentário:

\begin{abstract}
Assinalada desde muito tempo, a ação preponderante útero-ovariana sobre a vida mental, não nos é lícito duvidar que há um mecanismo complexo, um conjunto de atos reflexos, um conjunto de sensações múltiplas, uma elaboração cerebral inconsciente e, a sensibilidade física é um poderoso agente em que todos os fenômenos físicos como orgânicos, são intimamente ligados uns aos outros pelas relações de causalidade. (Garcia, 1901, p.15)
\end{abstract}

A relação entre problemas ginecológicos e desordens mentais seria corroborada pelo 'fato' de que a maior parte das alienadas teria lesões nos genitais. Segundo Picqué e Febvre, 89\% das loucas internadas no asilo Évrard sofriam de afecções ginecológicas. Na Casa de Saúde do Dr. Eiras, onde o próprio Garcia trabalhava, essa situação se repetia. O autor acrescenta que, na maioria dos casos, essas afecções precederiam a afecção mental ou a esta evoluiriam paralelamente. Garcia considerava de fundamental importância que, na ocasião em que desse entrada no asilo, a paciente passasse por um exame completo para detectar essas possíveis lesões, especialmente as de natureza inflamatória. Feito o diagnóstico, a cirurgia seria o procedimento mais indicado.

O autor lamenta que na Casa de Saúde do Dr. Eiras o número de operadas ainda era pequeno e relata os seis casos em que a cirurgia já tinha sido realizada, entre 1895 e 1900 (Garcia, 1901, p.21-33). O resumo dessas descrições ajuda a entender as concepções em jogo e a nos aproximar dos dramas reais envolvendo intervenções cirúrgicas. Segundo as observações clínicas, essas mulheres apresentavam sintomas como abuso de álcool, irritabilidade exagerada, melancolia, estupor, tentativas de suicídio, idéias de perseguição, alucinações etc., associadas a irregularidades menstruais, endometrites, papilomas, atresia do colo do útero e outros males que mereceram intervenções cirúrgicas. O caso de M.J. é exemplar. Brasileira, 29 anos, branca, casada, multípara, foi internada em maio de 1896 por se "comportar de maneira inapropriada", mantendo relações sexuais fora do casamento com "três homens de classe baixa". Internada e sem poder sair, passou a sofrer de 
"ninfomania" e a "lançar olhares libidinosos aos representantes do sexo oposto". O tratamento empregado foi uma curetagem uterina. Em setembro do mesmo ano, M.J. deixou a Casa de Saúde "curada". Mais tarde, porém, voltaram as perturbações e dessa vez ela foi internada no Hospício Nacional dos Alienados, onde veio a falecer. ${ }^{6}$

Pelas descrições percebe-se que se tratava de mulheres jovens a manifestar condutas desviantes. Na opinião dos médicos, tais condutas caracterizavam problemas mentais e eram consideradas suficientemente graves para justificar a reclusão. A lembrança dos antecedentes hereditários de cada uma, o que podia consistir nas mais variadas qualidades, contribuía para definir ou legitimar as decisões médicas. O mais impressionante é a facilidade com que era feita a associação entre problemas nos órgãos genitais e perturbações mentais. Garcia (1901) escreve como se fosse óbvia essa conexão e como se fosse mais natural ainda o recurso à cirurgia nos genitais como meio de pôr fim à alienação mental. A conclusão da tese revela, ainda, que os casos apontavam para a validade do argumento e para o sucesso do recurso empregado (p.35).

Contudo, na mesma época em que Garcia defendeu sua tese, já começava a aparecer outra faceta da questão da cirurgia e especialmente da extirpação dos genitais. Trata-se da discussão a respeito da importância da integridade desses órgãos para a saúde mental da mulher e para a manutenção do desejo sexual. O debate ocorrido em uma das sessões da Sociedade de Medicina e Cirurgia do Rio de Janeiro (Brazil-Medico, 1901, p.389) demonstra como tais dúvidas foram colocadas de maneira premente. Tudo começou quando o doutor Vieira Souto apresentou uma peça anatomopatológica do museu da Sociedade. Tratava-se de um fibroma do útero, extirpado por ele, de uma paciente da Casa de Saúde de São Sebastião. A doente sofria de constantes metrorragias e por isso decidiu-se pela ablação supravaginal do útero e de seus anexos. Vieira Souto traz o caso a público com o fim de acentuar o infundado receio, que tinham algumas mulheres, de perder o "senso genésico" após a intervenção cirúrgica. Esse temor, bastante difundido, acabava se tornando um fato extremamente grave, pois essas mulheres só procuravam o cirurgião em caso de moléstias já muito adiantadas. O médico coloca a necessidade de combater esse preconceito, que estaria sendo desmentido pelos dados. Pela sua experiência, das 24 ou 25 doentes em que praticou a castração útero-ovariana, duas conservaram intacto o seu senso genésico. ${ }^{7} \mathrm{E}$ acrescenta que, a partir do trabalho de Jaonny Roux, Psychologie de l'instincte sexuel, e de outros autores como Richet, Talbot, Havelock Ellis, Gloevecke, Jayle e Guinard, via finalmente confirmada sua observação. Sob a inspiração de Guinard, sentencia que não existe qualquer razão psicológica séria para que a castração seja definida como responsável pelo completo desaparecimento dos apetites sexuais e pelo impedimento absoluto da execução do ato venéreo.

O doutor Daniel de Almeida, que fala em seguida, diz já ter tratado dessa questão. Declara concordar com o orador precedente porque muitas das suas operadas, quando interrogadas a respeito, disseram não ter sofrido nenhuma alteração no tocante aos seus apetites sexuais. Já o doutor Moncorvo Filho pondera que cabe ao sistema nervoso a mais acentuada influência na perda ou não do senso genésico e que, por consenguinte, o fenômeno deve variar de acordo com as condições de cada doente operada (Brazil-Medico, 1901, p.389). 
Esse relato mostra que o assunto estava merecendo a atenção dos médicos e que não havia uma posição definitiva a seu respeito, mas parecia predominar a opinião de que a cirurgia não prejudicava o desejo sexual. Moncorvo Filho, entretanto, lembrou a preponderância dos nervos. Estava colocada a discussão em torno da sede do desejo sexual e da relação entre os genitais e as funções mentais. A tese de Garcia, defendida no mesmo ano, recomendava a cirurgia dos genitais como tratamento para a alienação mental que tinha a exacerbação do desejo como uma de suas possíveis manifestações.

Alguns anos mais tarde, já em 1904, assistiu-se a certa reviravolta nesse debate. A tese de Theodorico T. da Silva e Souza (1904) contribui de forma singular para compreendermos o que se passava. Esse autor escreve a primeira tese, segundo palavras dele mesmo, sobre o tema da insuficiência ovariana. Trata do conjunto de perturbações determinadas pela hipofunção da glândula ovárica (p.3). Traça um histórico da determinação desse quadro, iniciando por 1889, quando Brown Sequard apresentou à Sociedade de Biologia de Paris uma comunicação sobre a importância do líquido orquítico (testicular). O médico francês teria aplicado injeções desse líquido de origem animal em si mesmo e obteve como resultado um franco processo de rejuvenescimento. Brown Sequard foi o primeiro a considerar os testículos e os ovários como glândulas de secreção interna e a supor que essas secreções têm influência sobre o sistema nervoso. Segundo Souza, desde meados da década de 1890 haviam surgido trabalhos interessantes que procuravam demonstrar a existência e a importância dessas substâncias (p.14-21).

Boa parte desses trabalhos se dedicara a provar que, após uma ovariotomia, as mulheres sofreriam uma série de perturbações advindas da falta da secreção interna do ovário. Esse órgão passou então a ganhar importância, considerando-se toda a economia do corpo feminino. Tornou-se idéia comum e aceita a de que, além da secreção externa, que é a produção dos óvulos, o ovário também é uma glândula de secreção interna. As cirurgias de extração passaram a ser rediscutidas e desenvolveu-se a idéia da reposição das secreções internas quando a operação tinha sido realizada ou era imprescindível, em virtude de uma lesão. O método utilizado era a 'opoterapia ovárica', ou seja, tratamento que prevê a reposição das substâncias produzidas pelo ovário. Os resultados positivos desse tratamento já teriam sido observados por alguns médicos, entre eles o eminente Jayle, que aplicou o método em mulheres castradas (Souza, 1904).

Souza (1904) explica que uma extensa gama de problemas que acontecem na vida da mulher é devida ao ovário. Assim são esclarecidas as desordens físicas e mentais da puberdade: a secreção interna dos ovários atua nas modificações de todo o organismo feminino nessa época da vida. Doenças como a clorose, por exemplo, agora são descritas a partir dessa nova concepção. Na menopausa, seria a falta de tal secreção a grande causa de todos os males e desequilíbrios. O mesmo aconteceria quando, por outras razões, se privasse a mulher dos ovários ainda na fase produtiva de sua existência. Quando os ovários são extraídos cirurgicamente, estabelece-se uma espécie de menopausa artificial, e a mulher enfrenta o mesmo gênero de problemas que naquela fase da vida. A conseqüência mais destacada da castração se refere a perturbações mentais e diminuição do desejo e do prazer durante o coito. Ou seja, está referendada aqui a conexão entre a castração, as desordens mentais e a falta do desejo. Só que, dessa vez, a explicação passa especificamente pela determinação da função das substâncias produzidas nos ovários. 
O autor recorreu a estatísticas para demonstrar como esses fatos já estariam devidamente provados. As experiências com animais também teriam corroborado a nova teoria. Souza (1904) transcreveu tabelas referentes a experiências feitas na Europa (e repetidas no Brasil por ele próprio) com cadelas e coelhas. Em todos os casos, o método era de castração dos animais com posterior ingestão das substâncias produzidas nos ovários. No que diz respeito às mulheres, o autor afirmava que, depois de diagnosticada a insuficiência ovariana, o tratamento deveria consistir em dois meios. O primeiro era indireto: recomendação do casamento ou do exercício das funções sexuais, como forma de provocar a estimulação e despertar as funções do ovário, caso eles ainda existissem, mesmo que parcialmente. O segundo, mais indicado e seguro, consistia na 'opoterapia ovárica', a partir da utilização de ovários animais. Essa terapia já contava com três opções oferecidas pela farmácia: os ovários crus, o líquido ovárico e o ovário dissecado, também chamado de 'ovarina'. O médico deveria escolher a melhor opção para cada caso e prescrever a ingestão periódica. Souza afirma que a ingestão dessas substâncias seria mesmo capaz de restabelecer a produção das regras. Como prova final da adequação do tratamento, o médico descrevia dez casos de ovariotomia, às vezes aliada à histerectomia, devido à presença de quistos ou outras lesões. Em todos os casos foi efetuado o tratamento com ovarina, com melhora das pacientes. Nesses casos, os sintomas que serviram para diagnosticar a insuficiência ovariana foram principalmente os vapores de calor, cefaléia, dores e insônia.

A insuficiência ovariana tornou-se um tema recorrente a partir de então, pelo menos até a década de $1930 .{ }^{8} \mathrm{O}$ problema passou a ser enquadrado com o desenvolvimento de uma nova especialidade médica, a endocrinologia. Em 1917, a tese de A. Americano do Brazil citava a importância do médico francês Brown Sequard, pioneiro destacado e polêmico, no progresso dessa disciplina. O texto já fala em órgãos endócrinos e em hormônios. O trabalho de Gabriel Duarte Ribeiro, defendido em 1922, situa a insuficiência ovariana nesse contexto: como insuficiência das glândulas endócrinas. Descreve com detalhes a anatomia e a fisiologia dos ovários e apresenta de maneira mais refinada as conseqüências da castração. Explica como, após essa cirurgia, o útero sofre um processo de atrofia, da mesma forma que os órgãos genitais externos. As pacientes engordam muito e sofrem alterações importantes no sistema nervoso. $\mathrm{O}$ autor acrescenta que a melhor solução para esses casos seria o enxerto ovariano, realizado a partir da extração de um ovário de mulheres sadias, implantado nas castradas. O grande inconveniente dessa técnica seria a dificuldade em encontrar doadoras dispostas a ceder um ovário são.

Já que o método do enxerto tinha inúmeros inconvenientes, a opção mais empregada parece ter sido mesmo a reposição dos hormônios faltantes, a partir da administração de medicamentos. Esse fenômeno pode ser constatado quando analisamos as páginas da Revista de Gynecologia e d'Obstetrícia referentes à década de 1920, em que se destaca a venda de produtos com princípios hormonais.

A opoterapia ou o uso de 'soros hormônicos' parecia ser uma das grandes novidades da época e era anunciada como a solução para os mais diversos problemas. O composto Thelygan (Figura 1), por exemplo, que entre outras coisas continha o "extrato esterilizado dos ovários de vacas novas", era indicado para "todas as enfermidades da vida sexual feminina" como "nervosidade geral", "sobrecansaço após trabalhos físicos e intelectuais", 


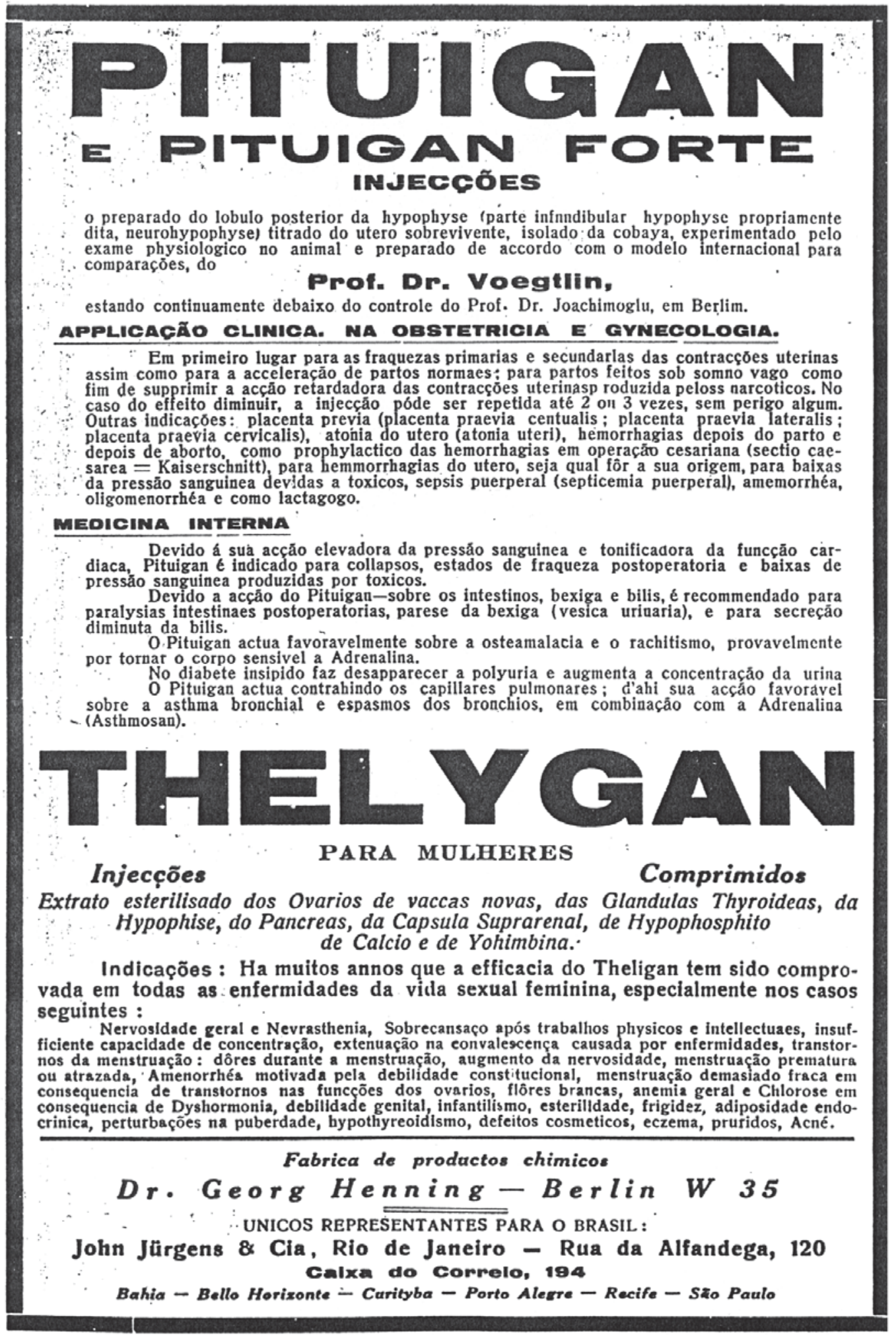

Figura 1 - Anúncio veiculado na Revista de Ginecologia e d'Obstetricia, v.22, n.6, jun. 1928 
"transtornos da menstruação", "clorose", "debilidade genital", "esterilidade", "frigidez", "defeitos cosméticos". Na mesma linha eram apresentados os Soros Hormônicos, de "sexos separados", propostos pelo doutor Aché (Figura 2), que teriam propiciado ótimos resultados em um caso de "psiconevrose com insuficiência ovariana". Deve-se notar, ainda, a inspiração eugênica desse anúncio, ilustrado pela imagem de um cavalo (que lembra o desejo de se criar um 'haras humano', comum entre alguns eugenistas da época), circundada pela frase

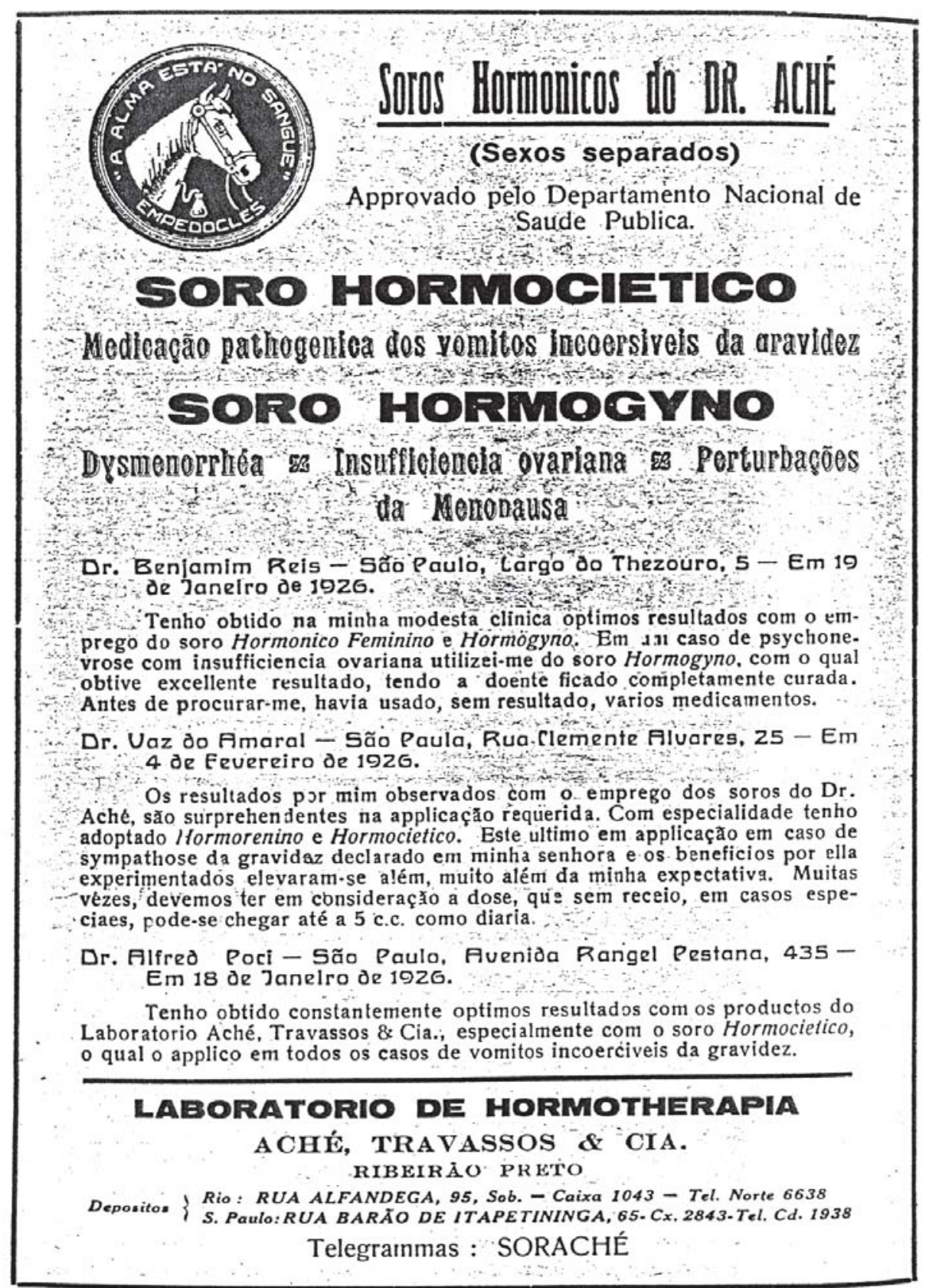

Figura 2 - Anúncio na Revista de Ginecologia e d'Obstetricia, v.20, n.11, nov. 1926 


\begin{abstract}
"A alma está no sangue". O Laboratório Silva Araújo (Figura 3) também promovia os "hormônios sexuais", constituídos de "associações pluriglandulares injetáveis", e as "hormovitaminas", uma associação dos "hormônios alimentares" aos "princípios das glândulas de secreção interna". Já especificamente para o climatério, podemos ver os medicamentos precursores da terapia de reposição hormonal, tão em voga atualmente, na ilustração do Klimakton (Figura 4) de "efeito comprovado" no combate aos "distúrbios do climatério", por meio da ação simultânea no sistema nervoso e glandular.
\end{abstract}

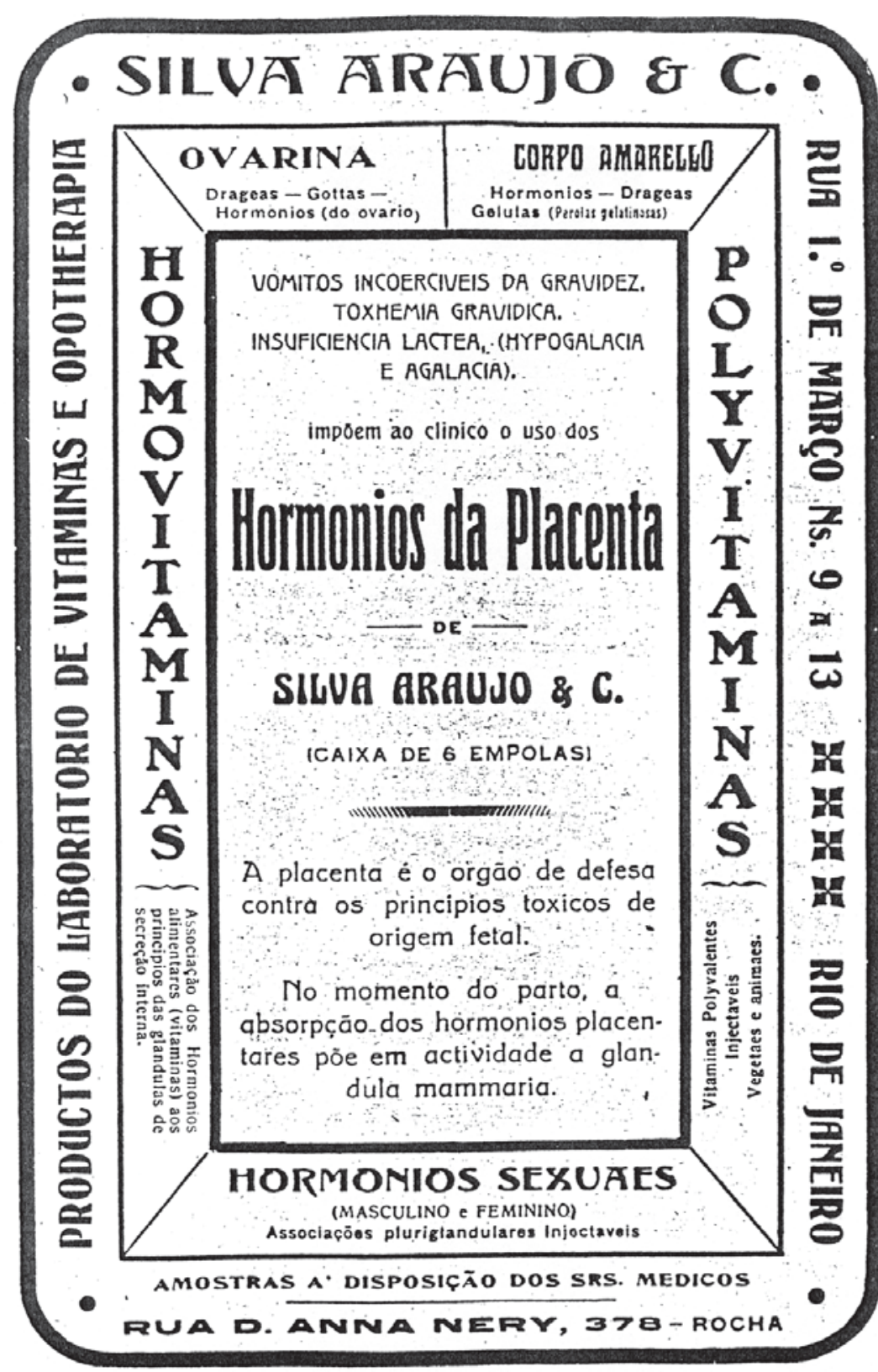

Figura 3 - Anúncio na Revista de Ginecologia e d'Obstetricia, v.21, n.9, set. 1927 


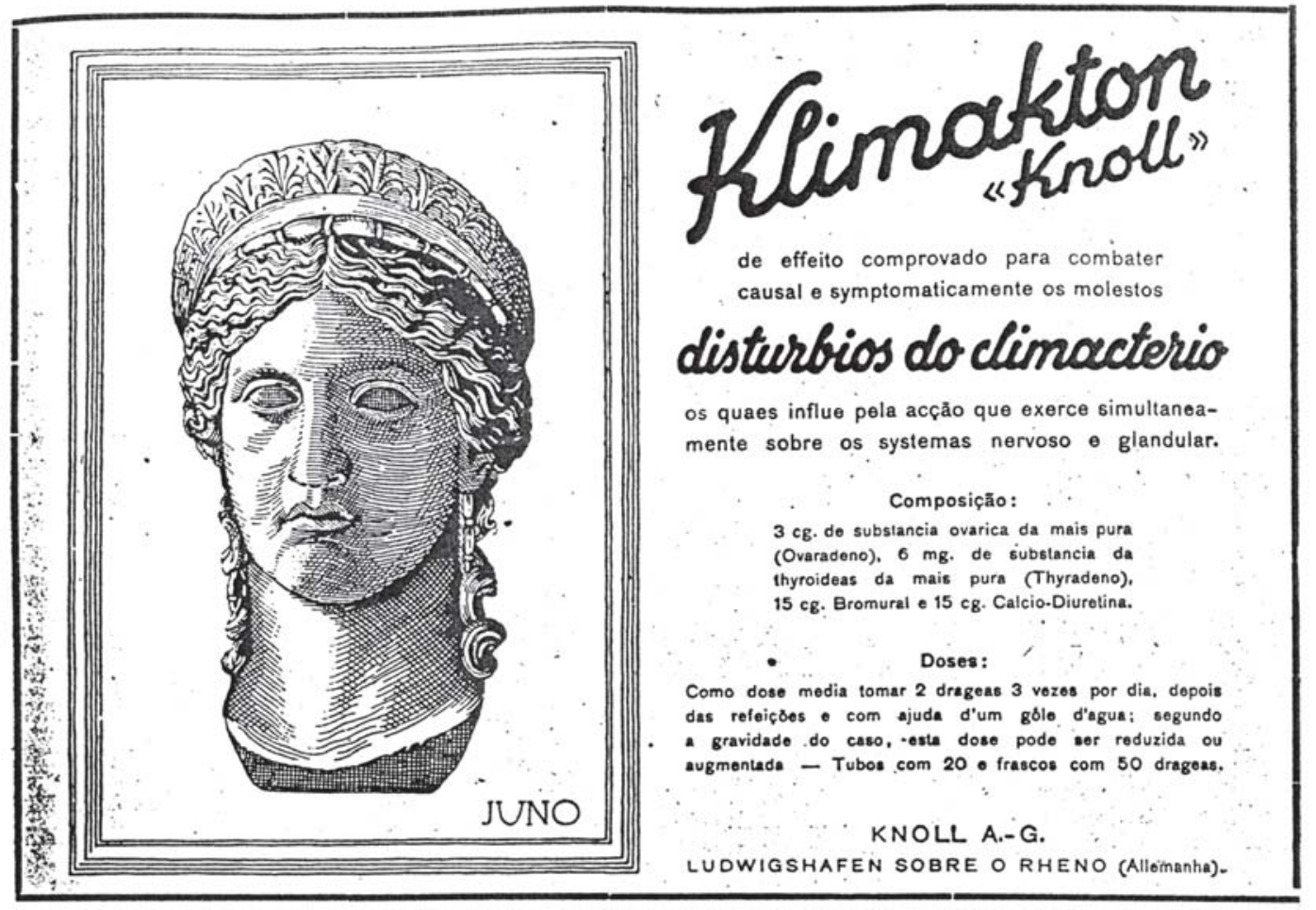

Figura 4 - Anúncio na Revista de Ginecologia e d'Obstetricia, v.22, n.6, jun. 1928

As descobertas científicas sobre os hormônios e o funcionamento do ciclo menstrual fizeram que os ovários se tornassem peças-chave na definição da natureza feminina. $\mathrm{Na}$ realidade, desde as últimas décadas do século XIX, no auge da prática da ovariotomia, debatia-se muito a importância desses órgãos para o bom funcionamento físico e mental da mulher, não só no Brasil mas também na Europa e nos Estados Unidos. Ornella Moscucci (1996, p.134-164), traçando as linhas gerais desse debate, afirma que muitos médicos eram contra a ovariotomia porque ela implicava a esterilização da mulher, a perda do desejo sexual e a aquisição de características masculinas. ${ }^{9}$ Essa dessexualização da mulher era percebida como uma ameaça ao casamento e à divisão sexual do trabalho, considerados os dois pilares de sustentação da sociedade e da nação. No caso da Inglaterra, contexto analisado pela autora, ao lado dos médicos que condenavam a ovariotomia estavam as feministas ${ }^{10}$, que acreditavam que a castração privaria a mulher de sua verdadeira essência e do cumprimento do seu destino de mãe e líder moral na sociedade. ${ }^{11}$

No começo do século XX, novos argumentos científicos que condenavam a ovariotomia vieram à tona. Nesse momento, o ovário foi convertido no órgão que condensa a feminilidade e capacita a mulher para a função reprodutiva. Sua presença tornou-se imprescindível, e a castração passou para segundo plano. Daí em diante, a apreciação da saúde da mulher e de sua própria identidade teve como referência seus ovários. As substâncias produzidas por esse órgão passaram a ditar a diferença em relação ao homem e às secreções dos testículos. Se antes as mulheres castradas ou as que estavam na menopausa eram 
desvalorizadas devido à falta de capacidade reprodutiva, passou-se então a acrescentar a isso a falta das substâncias que definiriam as características sexuais da mulher. Pode-se dizer que entrava em curso uma nova precisão a respeito da diferença, encampada pelas especialidades que se desenvolveriam no contexto das descobertas endocrinológicas.

É curioso que vemos reafirmada a conexão entre comportamento feminino e órgãos reprodutivos ou, mais especificamente, entre perturbações mentais ou morais e problemas com os ovários. Mas acontecia então uma verdadeira inversão. Se anteriormente, até a passagem para o século XX, prevalecia uma idéia de excesso, relativo à sexualidade feminina ou à própria concepção de feminilidade, tão marcadamente manifesta nos vários ciclos femininos, na nova etapa o que se destacava era uma imagem da falta, da chamada insuficiência ovariana, que representaria uma carência ou ausência de feminilidade, expressa de várias formas, do desejo sexual à capacidade de procriar. Acompanhando esse movimento, os tratamentos propostos também se alteraram. Em troca da extração dos ovários potencialmente perigosos, pregava-se a reposição das substâncias por eles secretadas, para que a mulher pudesse ter seu equilíbrio físico e mental recuperado. Saímos de uma lógica do excesso a ser coibido para uma lógica da falta que precisava ser suprida - perspectiva que permanece ainda hoje governando as idéias sobre as diferenças entre os gêneros e especialmente sobre a sexualidade de homens e mulheres. ${ }^{12}$

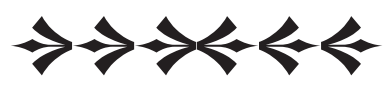

A descrição dessa passagem entre uma e outra lógica nos leva a tentar entender as influências que poderiam estar relacionadas ao processo. Certamente um evento fundamental nesse caso é a história da criação ou descoberta dos chamados hormônios sexuais.

O tema da criação dos hormônios tem sido objeto de um conjunto de trabalhos ainda restrito, mas extremamente poderoso em sua capacidade de nos fazer refletir sobre a ciência, de um modo geral, e sobre as relações de gênero, de modo particular. A 'descoberta', nomeação, comercialização e divulgação dessas novas entidades constituem um caso privilegiado para a análise da produção científica e de sua relação com os contextos que a envolvem e determinam. Diferentes aspectos têm sido abordados por autores de referência na produção de gênero e ciência, como Anne Fausto-Sterling (1992; 2000), Ruth Bleier (1997) e Londa Schiebinger (2001), ou nas linhas da antropologia do corpo, como Emily Martin (2006), e da história das intervenções na sexualidade, como Vern Bullough (1994). Talvez menos conhecidos por um público mais amplo, destacam-se dois trabalhos que, conjugados, desenham com muita propriedade a trajetória da constituição dos hormônios, considerando as negociações entre o campo científico propriamente dito, as intervenções médicas, o papel da indústria farmacêutica e de outros atores sociais importantes como os meios de comunicação e os movimentos sociais, especialmente o feminismo. Em Beyond the natural body: an archeology of sex hormones, Nelly Oudshoorn (1994) descreve o nascimento dos hormônios sexuais, os processos de medição e reprodução em laboratório, os debates em torno da nomenclatura, a comercialização e a dramática etapa da criação da pílula anticoncepcional e de seus primeiros testes em massa. Já Marianne Van Den Wijngaard (1997), em Reinventing the sexes: the biomedical construction of feminity and masculinity, 
procede a uma forte crítica feminista à ciência por meio da análise das teorias científicas que explicam a diferença entre os sexos, sobretudo no campo da neuroendocrinologia do comportamento.

Para o que nos interessa neste artigo, vale recorrer a alguns marcos fundamentais da história dos hormônios. Na versão profundamente detalhada de Oudshoorn (1994), a criação dos 'hormônios sexuais' se opera em um campo marcado pela interação entre três grupos principais: os clínicos, especialmente ginecologistas; os cientistas de laboratório, de fisiologistas a bioquímicos; e a indústria farmacêutica. Desde o final do século XIX até 1910 esses três grupos atuavam de forma independente, e os ginecologistas tinham uma posição de destaque, já que monopolizavam o saber sobre o corpo feminino e tinham acesso direto às pacientes para a realização de experiências e coleta de substâncias. Os cientistas de laboratório estavam trabalhando na pesquisa de hormônios por meio da utilização de animais, e as companhias farmacêuticas já recrutavam material em grande quantidade, vindo dos abatedouros. A partir da década de 1920, a posição das indústrias passou a ser determinante no campo, porque se tornou imprescindível a coleta de grande quantidade de material para processar o isolamento dos hormônios. Esse movimento corresponde também à passagem de um modelo biológico para um modelo bioquímico de entendimento do corpo humano.

Quanto à diferença entre homens e mulheres, se pelo menos até o final do século XIX era nítida a busca de um órgão que a explicasse e fundamentasse, já nas primeiras décadas do século XX o desafio era entender como as substâncias produzidas pelas gônadas operam o processo de diferenciação. Se antes o ovário poderia ser visto como centro condensador da feminilidade, assim como o testículo, da masculinidade, agora se tratava de descobrir o mecanismo de produção da feminilidade e da masculinidade. O paradigma bioquímico de causa e efeito determinava o que se deveria procurar e até onde as explicações deveriam chegar. Foi nesse contexto de busca pelas causas últimas dos fenômenos e de marcada relação entre gênero e sexo físico-corporal, substancializado em órgãos e agora em secreções internas, que se 'descobriram' os chamados hormônios sexuais.

Data de 1905 a formulação inicial do conceito de hormônio por Ernest Henry Starling, professor de fisiologia do University College em Londres, que já falava de substâncias químicas produzidas por determinados órgãos e capazes de afetar outros por meio da corrente sanguínea. Desde essa época até a década de 1920 predominou a noção de que os hormônios produzidos pelos ovários e pelos testículos seriam específicos, exclusivos de cada sexo e dotados de um papel único na determinação sexual. A presença de hormônios femininos só seria possível nas mulheres e determinaria as suas características sexuais, assim como os hormônios masculinos seriam exclusivos dos homens e determinariam as características masculinas. Contudo, a partir da década de 1920 as experiências realizadas com animais passaram a mostrar a presença dos dois tipos de hormônios em machos e fêmeas. Apesar das nítidas evidências científicas, não houve uma transformação imediata no campo. Os novos dados foram recebidos com muita resistência e incômodo, e somente uma década depois foi possível aceitar uma nova relação entre hormônios e sexo. $\mathrm{Na}$ década de 1930 ainda se descreviam, com espanto, as experiências nas quais se detectava a presença de hormônios femininos em machos e, notadamente com menos importância, 
se descrevia a presença de hormônios masculinos em fêmeas. Gradualmente passou-se a demonstrar uma diferença quantitativa na presença dos hormônios típicos de machos e fêmeas. Embora os cientistas tivessem identificado a não exclusividade na origem e função dos hormônios, os ginecologistas, na clínica, continuaram promovendo um modelo dualista. Como sabemos, o que prevalece até os dias de hoje é a noção comum que, se não reafirma a existência de hormônios específicos, postula uma relação íntima entre determinados tipos de hormônios e determinados tipos de corpos. Segundo Oudshoorn (1994), a idéia pré-científica do dualismo de gênero, tão pregnante desde a época vitoriana, continuou direcionando a produção e as descobertas científicas do início do século XX.

Um aspecto importante nesse processo se refere a como as pretensões relativas ao gênero também determinaram uma forma de acesso e tratamento diferenciado dos corpos de homens e mulheres por parte da ciência e da medicina. Já vimos que, do ponto de vista do acesso aos pacientes e também às substâncias por eles produzidas, os ginecologistas tiveram papel de destaque. Em contraste com o caso dos homens, as mulheres já representavam um contingente que tinha mais acesso aos médicos em busca de explicações e tratamentos para suas 'disfunções' relativas aos órgãos sexuais. Além disso, quando se começou a produzir os medicamentos com base na pesquisa hormonal, elas já estavam integradas à rede que vinha dos cientistas, passava pelos laboratórios e chegava aos clínicos. Esse fato fez que, também no plano dos testes e da comercialização dos produtos, as mulheres fossem muito mais atingidas. É notável sobretudo o fracasso na comercialização dos hormônios sexuais masculinos e na tentativa de criação de uma entidade clínica similar à menopausa (Oudshoorn, 1994). Essas condições materiais do campo, ao lado de uma distinção histórica no tratamento das sexualidades masculina e feminina, tiveram como um de seus efeitos a transformação mais radical do corpo feminino em um corpo hormonal. ${ }^{13} \mathrm{~A}$ partir de então, toda a economia corporal/mental feminina passaria a ser determinada pelos hormônios.

Ainda é necessário acrescentar que, seguindo a lógica que vinha do século XIX, de forte associação entre órgãos sexuais/reprodutivos e perturbações mentais, no novo modelo hormonal passa-se a tratar também dessas desordens em função dos hormônios. O que está por trás disso é uma perspectiva tão radicalmente centrada no poder dos mensageiros químicos, que uma série de outros fenômenos é percebida como englobada por eles. Se as mulheres, até a passagem para o século XX, eram governadas pelos ovários, os órgãos da feminilidade, agora elas o são pelos hormônios, as substâncias que determinariam seu sexo e seu gênero. Para entendermos isso é fundamental ter em mente o fato de que a história da pesquisa com os hormônios é também uma história pelo interesse no estudo dos comportamentos, em especial do que seria diferenciado em função do sexo. ${ }^{14}$

Nesse novo modelo, as perturbações que antes foram tratadas pela remoção dos ovários só poderiam ser solucionadas considerando o equilíbrio dos hormônios. É a partir daí que se pode compreender a transformação de um padrão, baseado no excesso, para outro, centrado na falta de feminilidade, e a decorrente necessidade de reposição das substâncias típicas das mulheres. A onda de comercialização dos produtos hormonais caminhou nessa direção. Oudshoorn (1994) comenta que os testes clínicos iniciais com essas drogas, ainda no início da década de 1920, eram restritos ao tratamento das desordens menstruais, principalmente amenorréia. Até 1927 os usos estavam mais circunscritos à clinica 
ginecológica, incluindo tratamento da menopausa, infertilidade e problemas nos órgãos genitais. Mas a partir de 1927 o principal laboratório europeu, o Organon, amplia as indicações para o campo da clínica psiquiátrica, criando oficialmente um novo mercado para os hormônios sexuais femininos. Alguns testes clínicos na Alemanha, por exemplo, utilizaram os hormônios em pacientes com esquizofrenia e melancolia. São descritas também prescrições nos casos de psicoses e depressões, atribuídas a desordens do ciclo menstrual, além de epilepsia, perda de cabelo, doenças nos olhos, diabetes, hemofilia etc. Já no final da década, portanto, os hormônios sexuais femininos eram recomendados para uma ampla e variada série de indicações (p.92-93).

A julgar pelo tipo de problemas tratados com os hormônios, percebe-se que mais uma vez estavam em cena perturbações que não eram restritas ou contidas nos corpos femininos, mas que indicavam desajustes no comportamento e, num sentido mais amplo, desordens sociais. Os hormônios pareciam ser as novas substâncias capazes de devolver a feminilidade esperada às mulheres que, por algum motivo, tinham perdido esse caminho. Se o padrão de comportamento sexual, social, reprodutivo e estético não se coadunava com o modelo de gênero esperado, a administração dos hormônios - as verdadeiras substâncias da feminilidade - poderia reconduzir as mulheres a seu devido lugar.

Nessa época, identifica-se na produção científica em torno dos hormônios uma justaposição entre o que seriam características físicas associadas ao sexo e aquelas relativas ao gênero. Isso porque parecia haver uma inextrincável conexão entre os planos físico e moral que, no contexto da endocrinologia nascente, se traduzia na redução dos comportamentos individuais a causas de origem orgânica e, mais precisamente, bioquímica. Tendo em vista os recentes debates teóricos a respeito da dicotomia sexo/gênero e suas oposições correlatas, pode-se sugerir que gênero é a categoria 'englobante' analiticamente, já que todas as referências relativas ao que seria o sexo ou o orgânico, nesse caso, são visivelmente estruturadas em função da lógica das relações de gênero dessa sociedade. $\mathrm{O}$ que notamos, então, no discurso sobre ovários e hormônios, não é somente uma descrição de sua função no corpo feminino, mas um tratado sobre como as mulheres se comportam em virtude de seus ovários e de seus hormônios. A remissão ao comportamento abre caminho para entendermos que esse discurso científico está, na realidade, retratando o 'gênero esperado' ou o comportamento adequado a essas mulheres.

É possível perceber que não estamos apenas descrevendo descobertas científicas ou tratamentos clínicos isolados, mas uma rede complexa de acontecimentos que tem no vetor de gênero uma de suas marcas fundamentais. Visto dessa forma, somos levados a pensar sobre as lógicas ou preocupações que estariam por trás desses eventos.

Parece ficar nítido que há uma resistente tentativa de encobrir o gênero a partir de uma lógica da substancialização da diferença. O objeto dessa substancialização pode variar, passando por exemplo dos ovários aos hormônios sexuais. Mas a referência a algum tipo de materialização do gênero permanece intacta, ou melhor, parece ir se aprimorando a cada descoberta científica. Percebe-se a pregnância de uma necessidade de 'essencialização' das diferenças entre homens e mulheres ao longo do último século, que remete necessariamente à tradição dualista que tem caracterizado a cultura ocidental moderna. Basicamente, as renovadas formas de 'essencialismo' têm implicado delimitar o que seria 
do plano natural, supostamente imutável, e o que se enquadraria no plano social ou cultural, passível de transformação. Um olhar mais atento ao discurso médico da passagem do século XIX ao XX, por exemplo, nos leva a perceber que é exatamente a instabilidade entre essas fronteiras, ou seja, a constatação da sua precariedade, que promove uma insistente reafirmação das oposições. ${ }^{15}$

A discussão sobre a marca dualista de nossa tradição de pensamento é bastante longa e espinhosa e, no mínimo, nos obriga a refletir sobre a ordem associada à constituição da oposição entre natureza e cultura. Mas, embora as soluções para 'escapar' aos dualismos não sejam fáceis, sua problematização em vários ramos da produção científica tem sido muito profícua. A perspectiva crítica da ciência que parte das teorias de gênero tem caminhado justamente em oposição a uma reificação costumeira dos dualismos. Uma das principais contribuições tem sido mostrar que a separação política, operada por algumas correntes feministas a partir da década de 1960, entre o domínio do sexo e o que mais tarde seria chamado de gênero tem tido conseqüências bastante complexas. Naquele momento era importante enfatizar os aspectos históricos e sociais do gênero e ignorar estrategicamente o domínio biológico, que acabou ficando a cargo dos cientistas, especialmente biólogos e endocrinologistas. As teóricas do gênero não tratavam da biologia, ou melhor, admitiam o biológico como dado, trabalhando apenas com os fatores culturais (Fausto-Sterling, 2000; Wijngaard, 1997). Só mais recentemente um grupo de mulheres cientistas, sobretudo biólogas, começou a rever essa história do gênero na biologia da diferenciação sexual e a mostrar como aquilo que é largamente definido como dado biológico imutável está permeado pelas concepções de gênero dominantes em nossa sociedade. Essa perspectiva tem sido bastante poderosa nas análises que tem produzido e certamente abre novas portas, tanto para a investigação da produção científica 'tradicional', quanto para o aprofundamento do debate teórico sobre gênero e sobre nossos marcantes dualismos.

\section{AGRADECIMENTO}

Agradeço às alunas do curso Gênero, Sexualidade e Ciência, ministrado em 2006 no Programa de Pósgraduação em Saúde Coletiva do Instituto de Medicina Social, da Universidade do Estado do Rio de Janeiro (Uerj), com as quais discuti as idéias aqui presentes.

\section{NOTAS}

${ }^{1}$ Para um detalhamento dessa discussão, ver Rohden, 2001.

${ }^{2}$ E. Showalter (1993, p.171-190) descreve como a cirurgia pélvica 'tornou-se moda' entre as mulheres na Inglaterra do século passado. A autora relaciona isso a um fenômeno mais geral de curiosidade médica com o corpo da mulher, que se traduz sobretudo na vontade de dissecá-lo e na utilização dos novos instrumentos de exame ginecológico. Com relação ao corpo masculino não havia tantas fantasias, e a idéia de abrir esse corpo não parecia tão fascinante, talvez pelo fato de o pênis e os testículos terem localização externa.

${ }^{3}$ C. Groneman (1994, p.346) afirma que, no final do século XIX, médicos americanos e europeus apontavam os problemas menstruais como a principal causa de doenças como a ninfomania e a histeria.

${ }^{4}$ A ovariotomia representou um fenômeno de grandes proporções, não apenas em relação às próprias mulheres que sofreram esse tipo de intervenção, mas também como técnica sobre a qual se consolidou a especialidade ginecológica. É notável que trabalhos médicos que historiam o desenvolvimento dessa especialidade dediquem capítulos específicos ao tema. Ver Cianfrani, 1960, p.272-287; Rozembaum, Peumery, 1990, p.113-121; e O’Dowd, Phillip, 1994, p.4004-4009. 
${ }^{5}$ Pelo menos na Europa, a castração parece ter sido usada também como método de controle da natalidade. No Brasil não encontrei dados significativos sobre esse ponto, a não ser a menção que Erico Coelho (1915) faz à situação francesa a partir da obra Fecondité de E. Zola. Coelho transcreve o seguinte trecho do livro, que considera o melhor relato sobre a queda da população na França: "De cima a baixo, do grande ao pequeno, bate moeda a hedionda indústria que faz infecundas as mulheres. Eis uma esposa a quem abre o ventre, de onde arrancam o cacho da vida repleto de óvulos. Eis uma virgem mutilada, da qual suprimem a maternidade em botão antes que o mesmo floresça. Corta-se, corta-se sempre e em todos os lugares sociais. Vós sabeis a que extremos chegamos. Nos hospitais são castradas duas a três mil mulheres por ano. Esse número é o dobro, pelo menos, nas clientelas particulares; pois aí não há testemunhas indiscretas nem registro de algum alcance. Somente em Paris, no espaço de quinze anos, a quantidade dessas operações deve ter sido de 30 a 40 mil. Enfim, calcula-se em quinhentos mil, por outro, em meio milhão, as mulheres na França, das quais amputaram ou arrancaram a flor da maternidade, como se fosse erva daninha. Em dez anos, a faca dos castradores de mulheres nos fez mal maior que as balas dos prussianos" (citado em Coelho, 1915, p.22-23).

${ }^{6}$ Esse caso é o mesmo relatado por Maia (1896, p.95), embora este autor não mencione o desfecho final com a morte da paciente. M. Engel (1997), em texto intitulado "Psiquiatria e feminilidade", analisou o mesmo caso.

7 Vieira Souto não esclarece se a grande maioria das mulheres restantes sofreram ou não a perda do "senso genésico", o que contrariaria a sua hipótese.

${ }^{8}$ Temos o registro das seguintes teses, além das já citadas no texto: Cardoso Junior, 1911; Moreira, 1921; Barretto, 1924; Barbosa, 1924; Teixeira, 1925; Ferrari, 1927; Fortuna, 1927; Costa, 1928; Cardoso, 1932; e Magalhães, 1934.

${ }^{9}$ A autora pondera que existiam significativas diferenças entre franceses e britânicos, que, segundo ela, estariam relacionadas à religião majoritária (catolicismo ou protestantismo) de cada nação. Os franceses se mostravam muito mais críticos à ovariotomia. A Academia de Medicina de Paris chegou a proclamar-se oficialmente contra a extirpação dos ovários em 1857, posição que seria revista mais tarde (Moscucci, 1996, p.143).

${ }^{10}$ As feministas inglesas localizavam o combate contra a ovariotomia no interior de uma campanha mais ampla contra a vivissecção. Em muitos momentos, vivissecção e misoginia estiveram associadas. É o caso da percepção corrente em 1888 de que os crimes cometidos por Jack o Estripador eram obra de um cirurgião da Universidade e Londres (Moscucci, 1996, p.158-159).

11 M. Sandelowski (1990, p.484) também se refere ao paradoxo implícito na prática de extração dos ovários para curar doenças, que acabava por tornar as mulheres estéreis e inaptas à função materna, considerada necessária à sua saúde física e mental. C. Groneman (1994, p.350-351), tratando dos Estados Unidos, argumenta na mesma direção.

${ }^{12}$ Gostaria de sugerir que os atuais investimentos do campo da sexologia com vistas a promover uma noção de satisfação sexual e mesmo de saúde sexual ideal compartilham dessa premissa de que há uma 'falta' a ser suprida no domínio da sexualidade, expressa na noção quantitativa de 'mais prática', ou qualitativa de 'mais satisfação'.

${ }^{13}$ Oudshoorn (1994) aprofunda essa análise ao mostrar como, por meio do uso da pílula anticoncepcional, as mulheres de praticamente todas as partes do mundo passariam a ter suas vidas sexuais e reprodutivas controladas pelos hormônios, carros-chefes da indústria farmacêutica.

${ }^{14}$ Ver especialmente sobre a conexão entre hormônios, cérebro e comportamento, as análises de Bleier (1997), sobre a naturalização das diferenças de gênero, e de Wijngaard (1997), sobre a teoria organizacional. Sobre a história das diferenças de gênero percebidas no cérebro, no contexto do século XIX, ver Russett, 1995.

15 Sobre a discussão teórica a respeito da instabilidade das diferenças e da dicotomia natureza/cultura, consultar Rohden, 2001, 2003b. 


\section{REFERÊNCIAS BIBLIOGRÁFICAS}

ARAUJO, Arthur de Castro.

Ovariotomia. Tese - Faculdade de Medicina do Rio de Janeiro, Rio de Janeiro. 1881.

ASSIS, Benigno Alfredo de.

Ovariotomia. Tese - Faculdade de Medicina do Rio de Janeiro, Rio de Janeiro. 1881.

BARBOSA, Mariano.

Da insuficiência ovariana. Tese - Faculdade de Medicina do Rio de Janeiro, Rio de Janeiro. 1924.

BARRETTO, José Freire de Mattos.

O enxerto ovariano, sua técnica e seus defeitos. Tese - Faculdade de Medicina do Rio de Janeiro, Rio de Janeiro. 1924.

BLEIER, Ruth

Science and gender: a critique of biology and its theories on women. S.l.: Teachers College Press. 1997.

BRAZIL, A. Americano do.

A doutrina endocrinológica. Tese - Faculdade de Medicina do Rio de Janeiro, Rio de Janeiro.

1917.

BRAZIL-MEDICO.

Rio de Janeiro. 1901.

BULLOUGH, Vern.

Science in the bedroom. New York: BasicBooks. 1994.

CARDOSO Junior, Pedro de Freitas. Da insuficiência ovariana. Tese - Faculdade de Medicina do Rio de Janeiro, Rio de Janeiro. 1911.

CARDOSO, Alberto Pimentel.

Correlação entre os princípios ovarianos e o psiquismo nas psicopatias. Tese - Faculdade de Medicina do Rio de Janeiro, Rio de Janeiro. 1932.

CARVALHO, Guilherme Affonso de. Ovariotomia. Tese - Faculdade de Medicina do Rio de Janeiro, Rio de Janeiro. 1873.

CIANFRANI, Theodore.

A short history of obstetrics and gynecology.

Springfield: Charles C. Thomas. 1960.

COELHO, Erico.

A mulher e a guerra. Rio de Janeiro: Instituto Histórico e Geográfico Brasileiro; Imprensa Nacional. 1915.

COSTA, Hilario Locques da. Estudo clínico da síndrome de insuficiência ovariana. Tese - Faculdade de Medicina do Rio de Janeiro, Rio de Janeiro. 1928.
ENGEL, Magali.

Psiquiatria e feminilidade. In: Del Priore, Mary; Bassanezi, C. (Ed.). História das mulheres no Brasil. São Paulo: Contexto. p.322-361. 1997.

FALCÃO, Alfredo Menna Barreto de Barros. Ovariotomia. Tese - Faculdade de Medicina do Rio de Janeiro, Rio de Janeiro. 1881.

FAUSTO-STERLING, Anne.

Sexing the body: gender politics and the construction of sexuality. New York: Basic Books. 2000.

FAUSTO-STERLING, Anne.

Myths of gender: biological theories about women and men. New York: Basic Books. 1.ed., 1985. 1992.

FERRARI, Felicio.

Enxerto ovariano. Tese - Faculdade de Medicina do Rio de Janeiro, Rio de Janeiro. 1927.

FONTES, Luiz Ribeiro de Souza.

Breves reflexões sobre os quistos do ovário e seu tratamento pela ovariotomia. Tese - Faculdade de Medicina do Rio de Janeiro, Rio de Janeiro. 1880

FORTUNA, Alberta Aranha.

Sobre a função ovariana e sua insuficiência. Tese Faculdade de Medicina do Rio de Janeiro, Rio de Janeiro. 1927.

GARCIA, Urbano.

Da intervenção cirúrgico-ginecológica em alienação mental. Tese - Faculdade de Medicina do Rio de Janeiro, Rio de Janeiro. 1901.

GOMES, Affonso Henriques da Costa.

Do melhor método de tratar o pedículo e suturar o ventre na ovariotomia. Tese - Faculdade de Medicina do Rio de Janeiro, Rio de Janeiro. 1883.

GRONEMAN, G.

Nymphomania: the historical construction of female sexuality. Signs, Chicago, v.19, n.2, p.337-367. 1994.

KENT, Susan K.

Sex and suffrage in Britain (1860-1914). London: Routledge. 1.ed., 1987. 1990.

MAGALHÃES, Nuno de Andrade.

Vitalidade do ovário fora do organismo (pesquisas pessoais). Tese - Faculdade de Medicina do Rio de Janeiro, Rio de Janeiro. 1934.

MAIA, Vicente José.

A menstruação na etiologia das nevroses e psicoses. Tese - Faculdade de Medicina do Rio de Janeiro, Rio de Janeiro. 1866. 
MARTIN, Emily.

A mulher no corpo: uma análise cultural da reprodução. Rio de Janeiro: Garamond. 2006.

MOREIRA, Alberto Alves da Silva.

Sobre a função ovariana e sua insuficiência. Tese Faculdade de Medicina do Rio de Janeiro, Rio de Janeiro. 1921.

\section{MOSCUCCI, Ornella.}

The science of woman: gynaecology and gender in England (1800-1929). Cambridge: Cambridge Univ. Press. 1.ed., 1990. 1996.

NUNES, Christovão Pereira.

Da ovariotomia antisséptica abdominal. Tese -

Faculdade de Medicina do Rio de Janeiro, Rio de Janeiro. 1883.

O'DOWD, Michael; Philipp, Elliot.

The history of obstetrics and gynaecology. New York: The Parthenon Publishing Group. 1994.

OUDSHOORN, Nelly.

Beyond the natural body: an archeology of sex hormones. London: Routledge. 1994.

REGO, Antonio Manoel Alves do.

Ovariotomia. Tese - Faculdade de Medicina do Rio de Janeiro, Rio de Janeiro. 1871.

REVISTA de Ginecologia e d'Obstetrícia. Rio de Janeiro. 1922-1931.

RIBEIRO, Gabriel Duarte.

Estudo clínico da insuficiência ovariana. Tese Faculdade de Medicina do Rio de Janeiro, Rio de Janeiro. 1922.

ROHDEN, Fabíola.

$A$ arte de enganar a natureza: contracepção, aborto e infanticídio na primeira metade do século XX. Rio de Janeiro: Ed. Fiocruz. (Coleção História e Saúde no Brasil). 2003a.

ROHDEN, Fabíola.

A construção da diferença sexual na medicina. Cadernos de Saúde Pública, Rio de Janeiro, v.19, n.2, p.201-212. 2003b.

ROHDEN, Fabíola.

Uma ciência da diferença: sexo e gênero na medicina da mulher. Rio de Janeiro: Ed. Fiocruz. (Coleção Antropologia e Saúde). 2001.

ROZEMBAUM, Henri; PEUMERY, J.-J.

Histoire illustrée de la ménopause. Paris: Les Éditions Roger Dacosta. 1990.

RUSSETT, Cynthia E.

Sexual science: the victorian construction of womanhood. Cambridge: Harvard University Press. 1.ed., 1989. 1995.
SANDELOWSKY, Margarete J.

Failures of volition: female agency and infertility in historical perspective. Signs, Chicago, v.15, n.3, p.475-499. 1990.

SANTOS FILHO, José Rodrigues dos. Ovariotomia. Tese - Faculdade de Medicina do Rio de Janeiro, Rio de Janeiro. 1873.

SCHIEBINGER, Londa.

O feminismo mudou a ciência? Bauru: Edusc. 2001.

SCULL, Andrew; FAVREAU, Diane.

The clitoridectomy craze. Social Research, New York, v.53, n.2, p.243-260. 1986.

SHOWALTER, Elaine.

Anarquia sexual: sexo e cultura no fin de siècle. Rio de Janeiro: Rocco. 1993.

SILVA, Caetano Ignacio da.

Ovariotomia: do aleitamento natural, artificial e misto em geral... Tese - Faculdade de Medicina do Rio de Janeiro, Rio de Janeiro. 1878.

SILVA, Francisco Gonçalves de.

Ovariotomia. Tese - Faculdade de Medicina do Rio de Janeiro, Rio de Janeiro. 1881.

SILVA, Joaquim Antonio Monteiro da. Amputação útero-ovariana. Tese - Faculdade de Medicina do Rio de Janeiro, Rio de Janeiro. 1883.

SILVA, Miguel Archanjo da.

Ovariotomia. Tese - Faculdade de Medicina do Rio de Janeiro, Rio de Janeiro. 1873.

SOUZA, Theodorico T. da Silva e. A insuficiência ovariana. Tese - Faculdade de Medicina do Rio de Janeiro, Rio de Janeiro. 1904.

TEIXEIRA, Carlos de Castro.

Contribuição ao estudo do enxerto ovariano. Tese Faculdade de Medicina do Rio de Janeiro, Rio de Janeiro. 1925.

VASCONCELLOS, Luiz Antonio da Fonseca. Da ovariotomia. Tese - Faculdade de Medicina do Rio de Janeiro, Rio de Janeiro. 1872.

VASCONCELLOS, Modesto Lins de. Ovariotomia. Tese - Faculdade de Medicina do Rio de Janeiro, Rio de Janeiro. 1895.

WIJNGAARD, Marianne Van Den. Reinventing the sexes: the biomedical construction of feminity and masculinity. Bloomingthon (Ind.): Indiana University Press. 1997. 